\title{
COMMENTARY
}

\section{Imagining Sustainability Beyond COVID-19 in India}

\author{
Bejoy K. Thomas, ${ }^{*}$ Soumyajit Bhar ${ }^{* *}$ and Shoibal Chakravarty ${ }^{* * *}$
}

\begin{abstract}
The COVID-19 lockdown in India saw a spate of news stories suggesting improvements in environmental conditions. In this article, we caution against optimistic narratives of environmental revival. First, we analyse air pollution data before and during the lockdown to show that these improvements were temporary and a by-product of the severe restrictions placed on the normal functioning of the economy. Second, drawing upon data on income and inequality, we suggest that the human suffering witnessed during the lockdown was a result of widening social disparities since the 1990s. We argue that environmental priorities cannot be separated from social concerns, and equity has to be at the centre of imagining sustainability beyond the pandemic.
\end{abstract}

Keywords: COVID-19; Equity; Environmentalism; Degrowth.

\section{INTRODUCTION}

India went into forced confinement with a national lockdown from March 25, 2020, in response to the COVID-19 pandemic. Even as the pandemic spiralled into an unprecedented public health, economic, and humanitarian crisis, anecdotes of environmental revival began to emerge in different parts of the country. In this article, we caution against such optimistic narratives

\footnotetext{
* Associate Professor in Humanities and Social Sciences. Indian Institute of Science Education and Research (IISER), Dr. Homi Bhabha Road, Pashan, Pune 411 008, India. bejoy@iiserpune.ac.in.

** Doctoral Student, Ashoka Trust for Research in Ecology and the Environment (ATREE), Bangalore, 17/589, M. G. Road, P. O. Chinsurah, Dist. Hugli 712101, India; soumyajit.bhar@atree.org.

Senior Researcher, Divecha Centre for Climate Change, Indian Institute of Science, Bangalore 560012, India; shoibalc@gmail.com.

Copyright (C) Thomas, Bhar and Chakravarty 2021. Released under Creative Commons Attribution-NonCommercial 4.0 International licence (CC BY-NC 4.0) by the author.

Published by Indian Society for Ecological Economics (INSEE), c/o Institute of Economic Growth, University Enclave, North Campus, Delhi 110007.
}

ISSN: 2581-6152 (print); 2581-6101 (web).

DOI: https://doi.org/10.37773/ees.v4i1.315 
of environmental revival. First, we analyse data on air pollution before and during the lockdown and suggest that the improvements in environmental indicators were unplanned and temporary. Given the scale of economic and social disruption, the environmental improvements were meagre. Second, drawing upon data on income and inequality, we argue that the scale of human suffering India saw during and after the lockdown was a result of widening disparities in income, wealth, and opportunities since the 1990s. A more considered position should take into account the implications for equity and justice when we think of sustainability during the pandemic.

\section{AIR POLLUTION BEFORE AND DURING THE LOCKDOWN}

Except for a handful of studies undertaken immediately after the lockdown (e.g., Lokhandwala and Gautam 2020; Kumar and Managi 2020), the narrative surrounding improvements in environmental indicators was driven by observable cues in nature, like stories of rivers appearing cleaner in Bangalore, or of air becoming clearer in Delhi, or of a stretch of the Himalayas becoming visible from Jalandhar.

We used weekly running averages of daily means of an Air Quality Index ${ }^{1}$ based on PM2.5 for four metropolitan cities that represent the major geographic regions in India-Delhi, Kolkata, Mumbai, and Chennai-to see the effects of the lockdown. Since the air is generally clearer during spring, which coincided with the beginning of the lockdown, any comparison with just the preceding months would be misleading. So we looked at data for the same period from previous years $(2019,2018$, and 2017) in addition to the 2020 data to understand the additional effects of the lockdown on air quality. Our results showed a general improvement in air quality compared to the previous years in all cities, though this was accompanied by local variations in weather and sources of pollution (Figure 1). It can be concluded that the national lockdown did improve air quality, but the effect wo temporary, especially given the strictness of the lockdown measures. Air pollution returned to pre-COVID-19 levels in China and Europe when lockdown restrictions were lifted (Carrington and Kommenda 2020). The case in India is unlikely to be any different.

Among other environmental indicators, data on river water quality showed mixed results with regards improvements following the lockdown (CPCB 2020). The lockdown is estimated to result in a $7 \%$ decrease in global annual $\mathrm{CO}_{2}$ emissions (Le Quéré et al. 2020). India's $\mathrm{CO}_{2}$ emissions reduced

\footnotetext{
${ }^{1}$ We sourced this data from AirNow, which collects current and historical air quality data. https://www.airnow.gov/. Accessed August 12, 2020.
} 
by an estimated 3.6\% (1.7\%-5.6\%) during January-April 2020 compared to annual emissions in 2019. The projected emissions reduction over the calendar year 2020 could vary between $5.2 \%$ and $8.7 \%$ (midpoint estimates) depending on the continuation of lockdown measures and the severity of the economic slowdown. However, these reductions have to be looked at not in isolation, but in the context of the disruption that the lockdown has caused to the economy and livelihoods.

Figure 1: Air pollution in major cities, 2017-2020 (January 1-June 30)

(A) Delhi

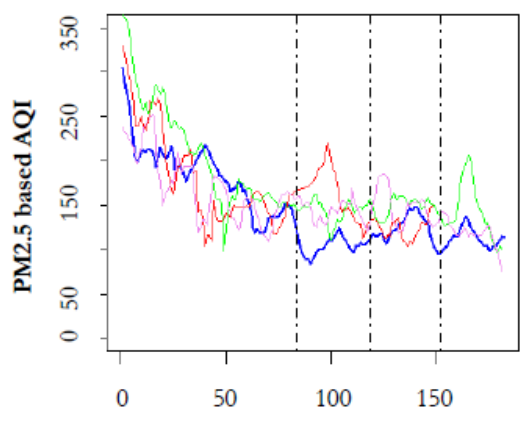

Days ( 01 January - 30 June)

(C) Mumbai

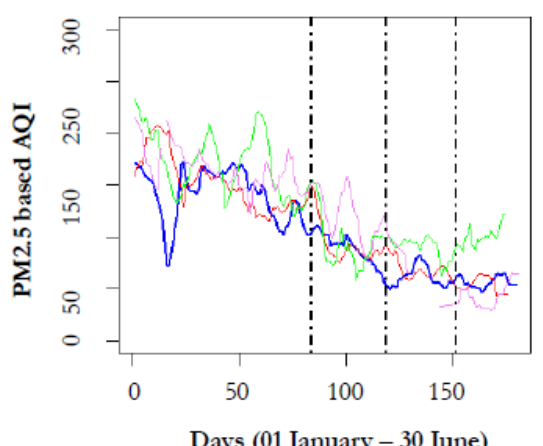

(B) Kolkata

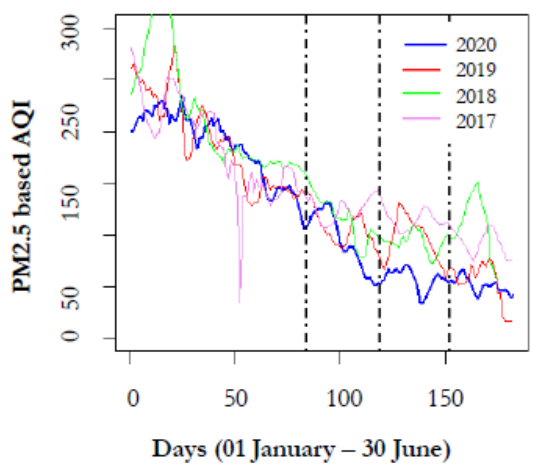

(D) Chennai

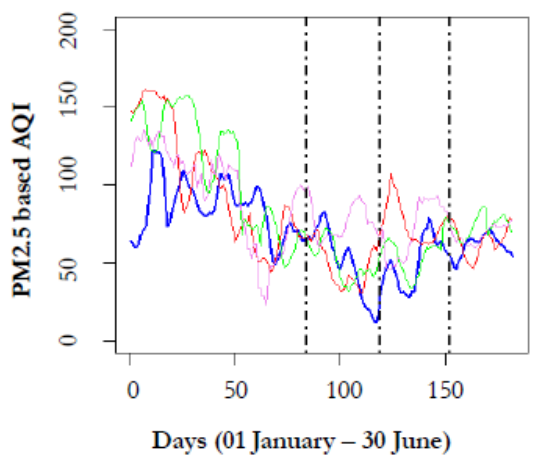

Data Source: AirNow, https://www.airnow.gov/.

Note: The dotted lines show the beginning (March 24) and middle (April 28) phases of the lockdown and the beginning of Unlock 1.0 (June 1) in India. 


\section{UNEQUAL SOCIAL IMPACT}

The Indian economy witnessed a massive slowdown in the aftermath of the lockdown. The gross domestic product (GDP) fell by 23.9\% during AprilJune 2020 compared to the same period during the previous year (GoI, 2020). The economic slowdown has had a significant impact on the livelihoods of urban and rural working populations, particularly casual workers and the self-employed in the informal sector (Kapoor 2020), urban migrant labourers, and small agriculturists, pushing a large number of them into hunger. The unemployment rate shot up to $23.52 \%$ from $7.76 \%$ between February and April 2020, with urban areas hit the hardest, and small traders, labourers, entrepreneurs, and salaried employees suffering the most. ${ }^{2}$ The Azim Premji University COVID-19 Livelihoods Survey (Kesar et al. 2020) found that $66 \%$ of the respondents had lost their jobs, with urban casual and self-employed workers being the worst affected. In the agricultural sector, $85 \%$ of the farmers surveyed could not harvest or sell their produce or sold it at a lower price than normal. Supply disruptions have in turn led to an increase in the prices of essential food items (Narayanan and Saha 2020).

The severe impact on the poor and vulnerable must be understood within the broader context of India's rising inequality in recent decades. Whether measured in terms of income, consumption, or wealth, various estimates based on diverse data sources all point to an increase in inequality between different socio-economic groups. Chancel and Piketty (2019) showed that inequality in incomes and top income shares showed a declining trend until the 1970s and began making a turnaround in the mid-1980s, owing to the shift from a regulated system to a market economy. They estimate that $22 \%$ of India's income is held by the richest $1 \%$-the highest income concentration since Independence. Anand and Thampi (2016) found a similar trend in wealth inequality, with wealth getting concentrated among the top $10 \%$ in recent decades. They also found a widening gap between the share of profits and wages in manufacturing after 2002, indicating that the gains from growth are disproportionately distributed in favour of the already wealthy. The income and employment impacts of COVID-19 are likely to be significantly higher on those working in the poorer informal sector, agricultural workers, and the self-employed, and will likely exacerbate inequality.

Our own estimates from the two nationally representative India Human Development Survey (IHDS) datasets (combined urban and rural sample)

\footnotetext{
2 This is as per the estimates of the Centre for Monitoring Indian Economy (CMIE). See https://unemploymentinindia.cmie.com/ Accessed September 18, 2020.
} 
indicate a high Gini coefficient of .53 during 2004-05 and .55 during 201112. We looked at expenditure on food, non-food, and luxury items ${ }^{3}$ across households belonging to different income deciles for 2011-12, the latest available IHDS data (Figure 2). Luxury items include those goods with the highest environmental impact. On average, households in the top decile spend 5.6-8.2 times more money than households in the bottom deciles on luxury consumption, whereas the ratio for food (2.1-2.4) and non-food (3.1-4.1) expenditure is far less. The consumption of the poorer and middle-income households is limited to subsistence or essentials, with the significant environmental footprint coming from the affluent.

Figure 2: Expenditure on food, non-food, and luxury consumption

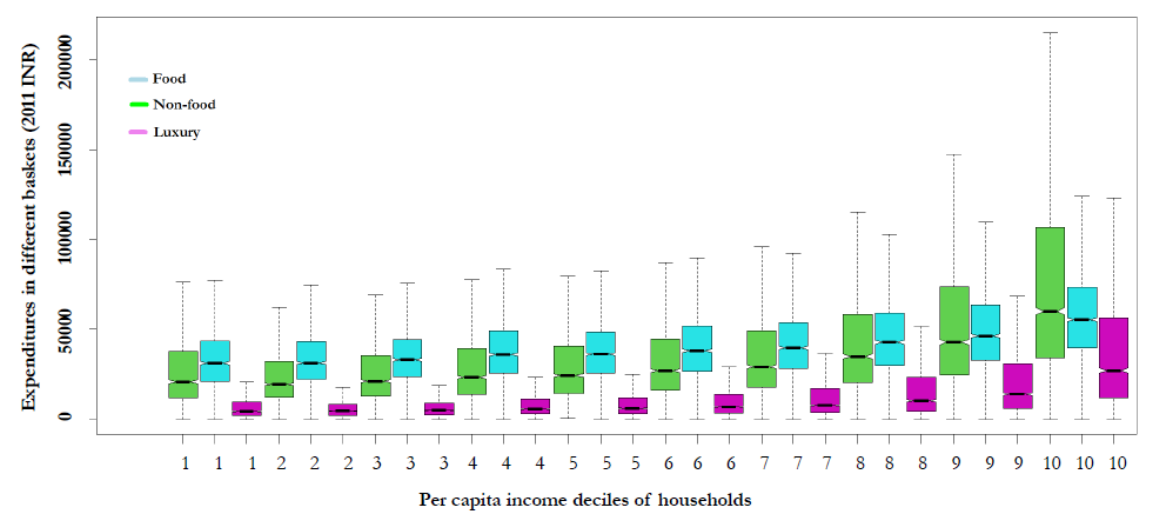

Source: Computed by authors using IHDS 2011-12 (rural and urban).

The mainstream media has extensively covered the plight and vulnerability of migrant labourers. A study based on the 2004-05 IHDS reported that short-term, seasonal migrants (defined as those who migrate for a period of less than six months out of distress and other reasons) are more vulnerable, tend to be poorer, and are more likely to belong to lower castes than longterm migrants (Desai and Chatterjee 2019). We found a comparable trend in the 2011-12 rural sample of IHDS. As Table 1 shows, short-term migration is likely to happen at lower levels of income. Looking at the marginalized communities-Dalits and Adivasis-separately, we found that $65 \%$ of all short-term migrants among these communities are from the bottom two income quintiles. It was possibly this section of migrants-

\footnotetext{
3 The food basket includes cereals, pulses, oils, eggs, and milk. The non-food basket comprises fuel, electricity, cable television/telephone, education, and services. The luxury basket includes jewellery, entertainment, vehicles, and recreation.
} 
short-term and vulnerable-who undertook precarious journeys back to their villages after the lockdown was announced (Rukmini 2020).

Table 1: Proportion of rural short-term migrants

\begin{tabular}{ccc}
\hline Income quintiles & Short-term migrants $(\%)$ & Non-migrants $(\%)$ \\
\hline 1 & 13.39 & 86.61 \\
\hline 2 & 10.39 & 89.61 \\
\hline 3 & 8.59 & 91.41 \\
\hline 4 & 5.77 & 94.23 \\
\hline 5 & 3.50 & 96.50 \\
\hline
\end{tabular}

Source: Computed from IHDS 2011-12 (rural)

\section{4. . IMAGINING SUSTAINABILITY}

The popular media narrative focused exclusively on visible changes in air and water to suggest that the environment benefitted from the lockdown. The studies undertaken immediately after the lockdown only reinforced this view, given that it is only expected that air quality would improve in the event of a shutdown of industrial activities and the suspension of vehicular traffic. However, these narratives paid less attention to the question of whether and how this could last beyond the lockdown, and more importantly, the normative question of whether this was tenable, given the disruptive impact that the lockdown had on livelihoods. A more reflective environmentalist response came from advocates of degrowth, who envision transforming production and consumption through downscaling by choice and in a participatory manner, at both the individual and national scale, thereby transitioning towards a sustainable future. The degrowth movement was quick to point out that a recession in a growth-centric economy can be devastating for the poor, and hence such an environmental revival is not tenable with the principles of justice (Hickel 2020).

In broad sympathies with this position (Bhar 2020), we see several useful pointers from the responses to the pandemic in India as we envision the future of sustainability. First, the environmental improvements from the drastic measures were not as significant as the severe social distress that they caused, hitting the poorest and most vulnerable hardest. Unless we undertake carefully considered policies and long-term interventions, the system will go back to business as usual and could even worsen the current already high levels of inequality. Second, expectations about the speed at which ecological recovery can happen are misplaced. Clean rivers are not an indication that river health and aquatic biodiversity, which have been adversely affected by long periods of industrial pollution, have been revived. Third, the environmental challenge is not just about regulating 
industrial growth, pollution, and greenhouse gas emissions, but also about addressing unsustainable consumption among the wealthy; concentration of incomes and wealth among a few; lack of opportunities for the marginalized; and effective non-existence of social security systems. Environmental priorities, therefore, cannot be separated from social concerns, and equity and justice will have to be at the centre of imagining sustainability beyond the pandemic.

\section{ACKNOWLEDGMENTS}

We thank the reviewers of the journal and Vinish Kathuria for comments on an earlier version.

\section{REFERENCES}

Anand, I., and A. Thampi. 2016. "Recent Trends in Wealth Inequality in India." Economic and Political Weekly 51 (50): 59-67.

Bhar, S. 2020. "Degrowth and COVID-19: Are We Drawing a Simplistic Connection?" Mongabay, 21 April. https://india.mongabay.com/2020/04/commentary-degrowth-and-covid-19-arewe-drawing-a-simplistic-connection/

Carrington, D., and N. Kommenda. 2020. "Air Pollution in China Back to preCOVID Levels and Europe May Follow" The Guardian, 3 June. https://www.theguardian.com/environment/2020/jun/03/air-pollution-in-chinaback-to-pre-covid-levels-and-europe-may-follow

Central Pollution Control Board. 2020. A Report on Impact of Lockdown on Water Quality of River Ganga. New Delhi: Ministry of Environment, Forest and Climate Change, Government of India.

Chancel, L., and T. Piketty. 2019. "Indian Income Inequality, 1922-2015: From British Raj to Billionaire Raj?" Review of Income and Wealth 65 (S1): S33-S62. https://doi.org/10.1111/roiw.12439.

Desai, S., and E. Chatterjee. 2019. "Male Migration from Rural India: Divergent Pathways to Long-Term and Short-Term Migration." 2019 Annual Meeting of Population Association of America, April 10-13, Austin, http://paa2019.populationassociation.org/uploads/192011.

Government of India. 2020. "Press Note on Estimates of Gross Domestic Product for the First Quarter (April-June) 2020-21". New Delhi: Ministry of Statistics and Programme Implementation, Government of India. http://www.mospi.gov.in/sites/default/files/press release/PRESS NOTEQ1 2020-21.pdf.

Hickel, J. 2020. "What Does Degrowth Mean? A Few Points of Clarification." Globalizations. https://doi.org/10.1080/14747731.2020.1812222. 
Kapoor, R. 2020. "The Unequal Effects of the Covid-19 Crisis on the Labour Market." The India Forum, 27 July. https://www.theindiaforum.in/article/unequaleffects-covid-19-crisis-labour-market.

Kesar, S., R. Abraham, R. Lahoti, P. Nath, and A. Basole. 2020. "Pandemic, Informality and Vulnerability: Impact of COVID-19 on Livelihoods in India." CSE Working Paper 2020-01. Bengaluru: Azim Premji University.

Kumar, S., and S. Managi. 2020, "Does Stringency of Lockdown Affect Air Quality? Evidence from Indian Cities." Economics of Disasters and Climate Change 4: 481-502. https://doi.org/10.1007/s41885-020-00072-1.

Le Quéré, C., R. B. Jackson, M. W. Jones, A. J. P. Smith, S. Abernethy, R. M. Andrew, A. J. De-Gol, D. R. Willis, Y. Shan, J. G. Canadell, P. Friedlingstein, F. Creutzig, and G. P. Peters. 2020. "Temporary Reduction in Daily Global $\mathrm{CO}_{2}$ Emissions During the COVID-19 Forced Confinement." Nature Climate Change 10: 647-653. https://doi.org/10.1038/s41558-020-0797-x.

Lokhandwala, S., and P. Gautam. 2020. "Indirect Impact of COVID-19 on Environment: A Brief Study in Indian Context." Environmental Research, 188, 109807. https://doi.org/10.1016/i.envres.2020.109807.

Narayanan, S., and S. Saha. 2020. "Urban Food Markets and the Lockdown in India.” Working Paper 2020-017. Mumbai: Indira Gandhi Institute of Development Research. https://doi.org/10.2139/ssrn.3599102

Rukmini, S. 2020. “Why India's 'Migrants' Walked Back Home.” Livemint, 28 May. https://www.livemint.com/news/india/why-india-migrants-walked-back-home11590564390171.html. 